E3S Web of Conferences 1, 33010 (2013)

DOI: $10.1051 / \mathrm{e} 3 \operatorname{sconf} / 20130133010$

C Owned by the authors, published by EDP Sciences, 2013

\title{
Assessment of heavy metals in sediments of the Sinos river basin, southern Brazil
}

\author{
I. L. Schneider $^{1}$, E. C. Teixeira ${ }^{2}$, M. L. K. Rodrigues ${ }^{2}$ and S. B. A. Rolim ${ }^{3}$ \\ ${ }^{1}$ Postgraduate Program in Remote Sensing - Federal University of Rio Grande do Sul (UFRGS), Brazil, \\ ismaelquimrs@yahoo.com.br \\ ${ }^{2}$ State Foundation for Environmental Protection and Postgraduate Program in Remote Sensing - Federal University of \\ Rio Grande do Sul (UFRGS), Brazil, gerpro.pesquisa@fepam.rs.gov.br \\ ${ }^{3}$ State Foundation for Environmental Protection, Brazil, metaisfepam@hotmail.com \\ ${ }^{4}$ Postgraduate Program in Remote Sensing - Federal University of Rio Grande do Sul (UFRGS), Brazil, \\ silvia.rolim@ufrgs.br
}

\begin{abstract}
The present study aimed to evaluate the content of $\mathrm{Cu}, \mathrm{Cr}, \mathrm{Ni}$, and $\mathrm{Zn}$ and their geochemical partitioning in sediments of the Sinos river basin in southern Brazil. This basin has a high population density and a great number of industries, especially metallurgy, electroplating works, steel mills, petrochemicals, and tanneries. The total metal concentrations were determined by X-ray fluorescence, and the concentrations in the sediment phases were determined by applying the BCR-701 sequential extraction method proposed by the Community Bureau of Reference of the European Community, using ICP/OES. Heavy metal contents were evaluated in the sediment fraction $<63 \mu \mathrm{m}$. Results in the industrialized and densely populated region showed an increase in the total concentrations for $\mathrm{Cu}, \mathrm{Cr}$ and $\mathrm{Zn}$, and in the mobile fractions for the sequentially extracted metals $\mathrm{Cu}, \mathrm{Cr}, \mathrm{Zn}$ and $\mathrm{Ni}$. $\mathrm{Cr}$ stood out particularly in the Portão stream, showing a total concentration of $1286 \mathrm{mg} \mathrm{kg}^{-1}$, due to the influence of tanneries in this region.
\end{abstract}

Key words: Heavy metals, Sediments, Sequential Extraction, BCR-701

\section{Introduction}

Heavy metals when dispersed in aquatic environments tend to deposit in the sediment, which besides having high retention capacity, have the potential of releasing pollutants (Passos et al., 2011). However, as determination of the total concentration of a metal in sediments makes no distinction between natural and anthropogenic components and the metal (Quevauviller $e t$ al., 1996; Relic et al. 2010; Passos et al., 2011), the quantification of potentially available or labile metals in sediments provides a better indicator of this differentiation. The procedures used to determine the levels of potentially mobile metals might involve sequential extraction techniques, where several selective reagents are used consecutively to extract metals associated with "stages operationally defined" from the sediment. These procedures aim at simulating changes in environmental conditions and thus predict the impact of a potential mobilization of metals on the surrounding environment (Bacon \& Davidson, 2008).
One technique often used is the sequential extraction procedure proposed by the Community Bureau of Reference (BCR) (now Standards, Measurement and Testing Programme), which involves three steps exchangeable metals associated with carbonates, reducible metals, and oxidizable metals (Pueyo et al., 2001; Quevauviller et al., 1996; Davidson et al., 1994; Davidson et al., 1999; Teixeira et al., 2003; Rodrigues \& Formoso, 2006; Passos et al., 2011).

In the present study, we evaluated the total concentrations and the geochemical distribution of $\mathrm{Cu}, \mathrm{Cr}$, $\mathrm{Ni}$ and $\mathrm{Zn}$ in sediments of the Sinos river basin to assess the potential mobility of these metals in watercourses.

\section{Materials and Methods}

Area of Study

The Sinos river basin is located in the Northeast of the state of Rio Grande do Sul, Brazil. It occupies an area of $3,820 \mathrm{~km}^{2}$ and encompasses all or part of 29 counties, of which 21 are part of the metropolitan area of Porto 
Alegre (MAPA), the state's capital. The Sinos River has its source at an altitude of $600 \mathrm{~m}$, its main course flows for $190 \mathrm{~km}$ and it finally discharges its waters at an altitude of $12 \mathrm{~m}$. The basin is inhabited by approximately 1.3 million people, representing $13 \%$ of the total population of the state concentrated in only $3.5 \%$ of its territory. The climate is subtropical with an annual average temperature of around $20^{\circ} \mathrm{C}$ and about $1350 \mathrm{~mm}$ of rain per year, well distributed over the four seasons (FEPAM, 2006).

The basin can be divided into three different regions, all of which related to the corresponding section of the river: upper, middle, and lower. As one moves downstream, the population density and urbanization, as well as the industrial concentration increase. Presently, industrial activity (especially metallurgy, electroplating works, steel mills, petrochemicals and tanneries), domestic sewage, and rice farming are the main sources of concern with regard to water quality of this river basin (FEPAM, 2006).

\section{Collection and preparation of samples}

Sediment samples were collected in February and August 2010, at eight points along the main course of the Sinos River and three tributaries (the Rolante River and the mouths of the Luiz Rau and Portão streams). Samples of surface sediments were collected by using PVC, Lshaped manual collector. The material collected was stored in plastic bags, cooled to $4{ }^{\circ} \mathrm{C}$ and sent to the laboratory, where the fraction with particle size $<63 \mu \mathrm{m}$ was separated by wet sieving. The content of interest was oven-dried at $37^{\circ} \mathrm{C}$ and was then finely homogenized in an agate mortar (Rodrigues \& Formoso, 2006).

\section{Chemical analyses}

The total concentrations of metals were determined by Xray fluorescence (XRF). The sediment samples were prepared in the form of pressed pellets and analyzed in the Laboratory of Analytical Geochemistry at the State University of Campinas.

The analyses of metal fractionation were performed by applying the sequential extraction procedure in three steps proposed by BCR (Pueyo et al., 2001). The procedure employed is described in Table 1. The determination of $\mathrm{Cu}, \mathrm{Cr}, \mathrm{Zn}$ and $\mathrm{Ni}$ concentrations in the extracts of the sequential extraction was performed in an inductively coupled plasma optical emission spectrometer (ICP-OES) of the Laboratory of Soil Science, Federal University of Rio Grande do Sul.

In this study, a fourth step corresponding to the residual fraction was considered, to evaluate the content of metal bound to the silicate matrix or to the crystalline oxides of $\mathrm{Fe} / \mathrm{Mn}$, which are not released under natural conditions. This fraction was determined by the difference between the sum of three steps sequentially extracted in relation to the total content of metals previously determined by XRF.

The accuracy of the sequential extraction procedure was verified by analysis in triplicate of the certified reference material for river sediments (BCR-701), with mean recoveries of $85-104 \%$ for $\mathrm{Cr}, \mathrm{Cu}, \mathrm{Ni}$ and $\mathrm{Zn}$. For quality control of total metals concentrations by XRF, we analyzed two reference materials (GSS-2 and GSS-5), showing mean recoveries of $88-105 \%$ for the metals studied. The determination of metal concentrations was performed in duplicate, and the accuracy was measured by the coefficients of variation $(<10 \%)$.

\section{Results and Discussion}

Table 2 shows the total concentrations of metals and Figure 1 illustrates the percentage distribution of $\mathrm{Cu}, \mathrm{Cr}$, $\mathrm{Zn}$ and $\mathrm{Ni}$ in the four geochemical phases of sediments. The mean availability potential, measured by the ratio between the sum of concentrations in the three mobile phases and the total content, was as follows: $\mathrm{Zn}(53 \%)>$ $\mathrm{Cr}(37 \%)>\mathrm{Ni}(36 \%)>\mathrm{Cu}(33 \%)$.

When analyzing Table 2, we seen that from point SI 066 on there is an increase in the concentrations of $\mathrm{Cu}$, $\mathrm{Zn}$ and $\mathrm{Cr}$, and we point out the high total concentration of $\mathrm{Cr}\left(1286 \mathrm{mg} \mathrm{kg}^{-1}\right)$ at the mouth of the Portão stream. Figure 1 shows that from point SI 066 on there is also an increase in the potentially mobile phases of $\mathrm{Cu}, \mathrm{Cr}, \mathrm{Ni}$ and $\mathrm{Zn}$, probably due to an increase in population density and number of industrial plants.

Table 1. Sequential extraction procedure

\begin{tabular}{|c|c|c|}
\hline STEPS & REAGENTS & SEDIMENT PHASES \\
\hline 1 & Acetic acid $0.11 \mathrm{M}$ & Exchangeable - water and acid soluble species \\
\hline 2 & $0.10 \mathrm{M}$ hydroxylamine hydrochloride, $\mathrm{pH} 1.5$ & $\begin{array}{l}\text { Reducible - species associated with oxides and } \\
\text { iron and manganese hydroxides }\end{array}$ \\
\hline 3 & $\begin{array}{l}1.0 \mathrm{M} \text { ammonium acetate, after digestion with } \\
8.8 \mathrm{M} \text { hydrogen peroxide at } \mathrm{pH} 2\end{array}$ & $\begin{array}{c}\text { Oxidizable - species bound to organic matter and } \\
\text { sulfides }\end{array}$ \\
\hline $4^{*}$ & $\begin{array}{c}\text { Total concentration minus the sum of the } \\
\text { previous three steps }\end{array}$ & $\begin{array}{c}\text { Residual - species associated with the silicate } \\
\text { matrix }\end{array}$ \\
\hline
\end{tabular}

Source: Pueyo et al. (2001). ${ }^{*}$ Adopted herein. 
Table 2. Total metal concentrations in sediment samples $\left(\mathrm{mg} \mathrm{kg}^{-1}\right.$, d.w., fraction $\left.<63 \mu \mathrm{m}\right)$. The codes of the points indicate the distance in kilometers from the sampling point to the mouth of the Sinos River.

\begin{tabular}{ccccc}
\hline Site & $\boldsymbol{C r}$ & $\boldsymbol{C u}$ & $\boldsymbol{N i}$ & $\boldsymbol{Z n}$ \\
\hline SI 188 & 120.6 & 69.8 & 39.2 & 132.3 \\
Rolante river & 112.4 & 74.2 & 54.1 & 120.9 \\
SI 096 & 116.0 & 69.1 & 41.5 & 111.7 \\
SI 066 & 137.7 & 75.8 & 48.0 & 149.4 \\
Luiz Rau stream & 128.2 & 121.0 & 34.9 & 289.2 \\
SI 048 & 161.9 & 78.3 & 43.4 & 174.6 \\
Portão stream & 1,286 & 83.9 & 50.3 & 226.4 \\
SI 036 & 204.4 & 83.7 & 40.3 & 219.3 \\
SI 028 & 182.7 & 96.1 & 47.5 & 214.4 \\
SI 019 & 177.3 & 100.8 & 43.5 & 316.3 \\
SI 008 & 168.4 & 109.5 & 41.1 & 313.7 \\
\hline
\end{tabular}
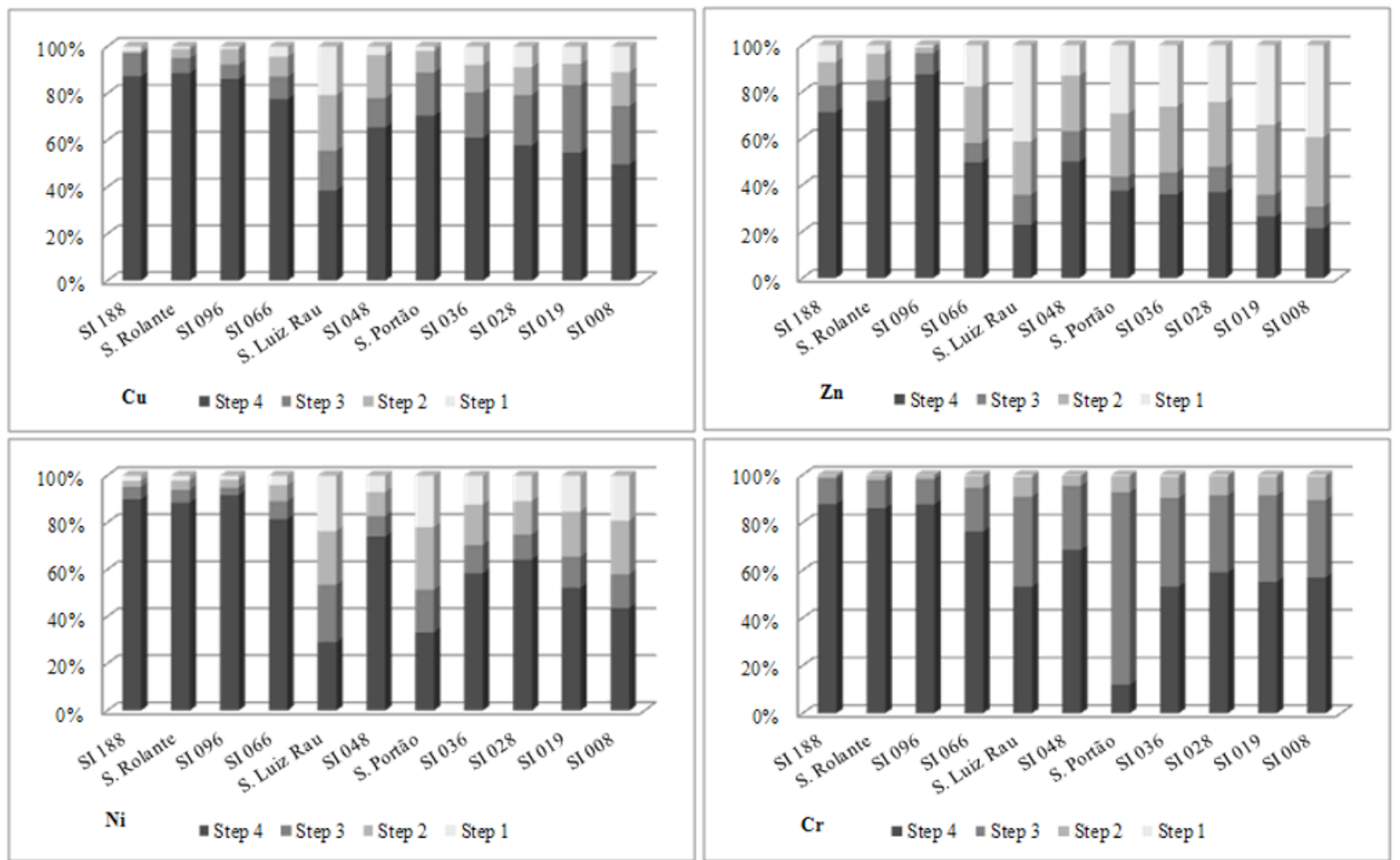

Fig. 1. Geochemical distribution of $\mathrm{Cu}, \mathrm{Zn}, \mathrm{Ni}$ and $\mathrm{Cr}$ in the sediments of the Sinos basin (Step $1=$ exchangeable fraction and bound to carbonates; Step 2 = reducible fraction; Step 3 = oxidizable fraction; Step $4=$ residual fraction).

The total concentrations of $\mathrm{Cu}$ are shown in Table 2. From Figure 1 on, we see that there is an increase in the potential mobility as we reach the mouth of the Sinos River, especially at the Luiz Rau stream, where it reaches $60 \%$. $\mathrm{Cu}$ was extracted mainly in the reducible and oxidizable fractions of the sequential extraction procedure, as reported by Davidson et al. (1994) and Vymazal et al. (2010).

Similarly, we found an increase in the total $\mathrm{Zn}$ concentrations (Table 2) and its potential mobility (Figure 1) in the lower section of the Sinos basin. Zn, frequently associated with $\mathrm{Fe}$ and $\mathrm{Mn}$ oxides (hydroxides and oxyhydroxides), was extracted mainly in the reducible phase (Vymazal et al., 2010). Moreover, this element also occurred in the exchangeable phase. The mobility increased from about $28 \%$ (SI 188, the source of the Sinos River) to almost $80 \%$ at some points (Luiz Rau stream, SI 019 and SI 008).

The total Ni concentrations (Table 2) showed no significant variations throughout the basin. However, when analyzing the mobility potential of Ni (Figure 1), we observe an increase in this metal in the exchangeable 
fractions from point SI 066 on. Noteworthy are the high percentages of mobility observed for the Luiz Rau and Portão streams (approx. $70 \%$ ).

For $\mathrm{Cr}$, there was also an increase in total concentrations (Table 2) from the lower section of the Sinos basin. However, it is important to highlight the concentration found in the Portão stream (1286 $\mathrm{mg} \mathrm{kg}^{-1}$ ), which is higher than the background value of the study area, not reported in the present study. As the metals highlighted above, there is an increase in the mobile fractions (Figure 1) from point SI 066 on. $\mathrm{Cr}$ was extracted mainly in the oxidizable fraction, indicating its binding to organic matter (Rodrigues \& Formoso, 2006; Vymazal et al., 2010). As for Portão stream, $1039 \mathrm{mg} \mathrm{kg}^{-}$ 1 , equivalent to $81 \%$ of the total concentration of this metal, were extracted in the third step of the sequential extraction. These high $\mathrm{Cr}$ levels are environmental markers of effluents from tanneries, as already reported by Rodrigues \& Formoso (2006), and they possibly reflect the influence of around 40 tanneries located in that region (FEPAM, 2006).

This similar behavior of increased of potentially mobile concentrations of $\mathrm{Cu}, \mathrm{Cr}, \mathrm{Zn}$ and $\mathrm{Ni}$ may be associated with anthropogenic contributions in the lower section of the Sinos basin. Among these contributions, there are the release of industrial and domestic effluents, urban runoff, the contribution of agricultural areas, vehicular traffic, and the burning of fossil fuels.

\section{Conclusions}

Analysis of sediments from the Sinos basin shows an increase in heavy metals concentrations nearer to the river mouth. From point SI 066 on, with its higher population density and higher number of industrial plants (mainly metal works, electroplating works, and tanneries), there is both an increase in the total concentrations $(\mathrm{Cu}$, $\mathrm{Cr}$ and $\mathrm{Zn}$ ) as in the sequentially extracted mobile fractions $(\mathrm{Cu}, \mathrm{Cr}, \mathrm{Ni}$ and $\mathrm{Zn})$. Although $\mathrm{Ni}$ did not show significant variations in total concentrations throughout the basin, it shows potential mobility of up to $70 \%$ in the Luiz Rau and Portão streams. $\mathrm{Cu}$ and $\mathrm{Zn}$ concentrations showed similar behavior, with a higher potential mobility for $\mathrm{Cu}(61 \%)$ and $\mathrm{Zn}(77 \%)$ in the Luiz Rau stream. $\mathrm{Cr}$ concentrations also increased in the lower section of the Sinos basin, especially in the Portão stream, with total concentration of $1286 \mathrm{mg} \mathrm{kg}^{-1}$ and potential mobility of $88 \%$. Therefore, by using sequential extraction as a tool for assessing the mobility of heavy metals in sediments, it is possible to estimate the behavior and potential availability of pollutants in the environment.

\section{References}

Bacon JR, Davidson CM. Is there a future for sequential chemical extraction? Analyst 2008; 133:25-46.

Davidson CM, Thomas RP, Mcvey SE, Perala R, Littlejohn D, Ure AM. Evaluation of a sequential extraction procedure for the speciation of heavy metals in sediments. Anal Chim Acta 1994; 291:277-286

Davidson CM, Ferreira PCS, Ure AM. Some sources of variability in application of the three-stage sequential extraction procedure recommended by BCR to industrially contaminated soil. Fresenius J Anal Chem 1999; 363:446-451.

FEPAM - Fundação Estadual de Proteção Ambiental, 2006. Qualidade das águas da bacia hidrográfica do rio dos Sinos. http://www.fepam.rs.gov.br/qualidade/qualidade_sin os/sinos.asp

Passos EA, Alves JPH, Garcia CAB, Costa ACS. Metal Fractionation in Sediments of the Sergipe River, Northeast, Brazil. J Braz Chem Soc 2011; 22:828835.

Pueyo M, Sastre J, Hernández E ... [et al.] Prediction of trace element mobility in contaminated soils by sequential extraction. J Environ Qual 2003; 32:2054-2066.

Quevauviller Ph, Rauret G, López-Sánchez JF, Rubio R, Ure A, Muntau H: 1996, The certification of the EDTA-extractable contents (mass fractions) of $\mathrm{Cd}$, $\mathrm{Cr}, \mathrm{Ni}, \mathrm{Pb}$ and $\mathrm{Zn}$ in sediment following a three-step sequential extraction procedure - EUR17554 EN. Office for Official Publications of the European Communities, BCR Information, Luxembourg, 59 pp.

Relic D, Dordevic D, Popovic A, Jadranin M, Polic P. Fractionation and potential mobility of trace metals in Danube alluvial aquifer within an industrialized zone. Environmental Monitoring and Assessment 2010; 171:229-248.

Rodrigues MLK, Formoso MLL. Geochemical distribution of selected heavy metals in stream sediments affected by tannery activities. Water Air Soil Pollut 2006, 169:167-184.

Salomons W, Förstner U. 1984. Metals in the hydrocycle. Springer-Verlag, Berlin, 349p.

Salomons W. Environmental impact of metals derived from mining activities: processes, predictions, prevention. J Geochem Explor 1995; 52:5-23.

Teixeira EC, Rodrigues MLK, Alves MFC, Barbosa JR: 2003, 'Study of geochemical distribution of heavy metals in sediments in areas impacted by coal mining', in J. Locat, R. Galvez-Cloutier, R. C. Chaney and K. Demars (eds.), Contaminated Sediments: Characterization, Evaluation, Mitigation/ Restoration, and Management Strategy Performance, ASTM STP 1442, ASTM International, West Conshohocken, PA, USA, pp. 72-86.

Vymazal J, Svehla J, Kröpfelová L, Nemcová J, Suchy V. Heavy metals in sediments from constructed wetlands treating municipal wastewater. Biogeochemistry 2010; 101:335-356. 